\title{
The Effects of Achromatic and Chromatic Color Schemes on Participants' Task Performance in and Appraisals of an Office Environment
}

\section{Elif Öztürk, Semiha Yılmazer, ${ }^{*}$ Sibel Ertez Ural}

Faculty of Art, Design and Architecture, Department of Interior Architecture and Environmental Design, Bilkent University, Bilkent, Ankara 06800, Turkey

Received 24 November 2010; revised 14 January 2011; accepted 21 January 2011

Abstract: This study explores the effects of chroma on participants' performance and environmental appraisal of an office. The research was conducted in a full-scale experimental room designed as a private office where achromatic and chromatic color schemes with coequal values were applied. Sixty participants were assigned tasks and given a questionnaire to appraise the spatial color schemes. The findings show that chroma significantly affects performance and space appraisal. In terms of accuracy and time spent performance scores measured significantly better in the room with the chromatic scheme than those in the room with the achromatic scheme. The office with the chromatic scheme was found to be more pleasant, attractive, satisfying and dynamic than the one with the achromatic scheme, whereas the achromatic scheme was thought to be more formal and harmonious. Categorization of pleasantness, harmony, dynamism and spaciousness by factor analysis also showed differences between the achromatic and chromatic schemes. (c) 2011 Wiley Periodicals, Inc. Col Res Appl, 37, 359-366, 2012; Published online 12 August 2011 in Wiley Online Library (wileyonlinelibrary.com). DOI 10.1002/col.20697

Key words: office environment; chroma, achromatic and chromatic color schemes; environmental appraisal; task performance

\section{INTRODUCTION}

Color is a powerful design element, serving as a tool of communication between people and the built environment.

\footnotetext{
*Correspondence to: Semiha Yılmazer (e-mail: semiha@bilkent.edu.tr).
}

(C) 2011 Wiley Periodicals, Inc.
It plays an important role in environmental design, informing theme, ambiance, image, function, built form, location and direction. The correct use of color can enhance peoples' interaction with their environment. In addition, the appropriate usage of color combinations is also relevant for presenting the aesthetic, symbolic and cultural meanings of an environment. ${ }^{1}$

In interior color design the fundamentals must first be understood, and from there, designers must find the ultimate color solutions for specific design situations. Throughout the design process, designers should consider the psychological properties of color and the effects of color on spatial dimensions. Whether it is possible to measure accurately psychological responses to color is debatable; cultural, geographical, economical, and educational differences affect generalizations on this issue. However, collective findings have shown that most people exhibit the same reactions to certain colors, and therefore color impressions, associations and their general characters can guide designers to understand how people may perceive a space. ${ }^{2}$

The functions of color in an office environment are varied. It can define the space's atmosphere or solidify a company's brand. ${ }^{3}$ With the increasing amount of time people are spending at work, the psychological effects of office color is becoming a topic of study. In terms of psychological conditions of workers, research in literature has focused on how color and color combinations affect workers' mood, productivity, and subjective impressions. Numerous studies have also shown that environmental factors (air quality, thermal comfort, spatial comfort, privacy, office noise control, building noise control, lighting comfort, color and workstations) affect workers' perceptions and behaviors. ${ }^{4,5}$

Many studies provide clues to enhancing interior color design. However, as Kwallek et al. ${ }^{6}$ stated, simply viewing 
pictures or slides of interiors cannot result in a subjective evaluation; people need to be exposed to real interior environments. In addition, studies about the relation between color and human performance that were conducted in sets with isolated stimulus or restricted objects ${ }^{7}$ were not enough to provide conclusive evidence.

Kwallek et al. $^{8}$ designed an experiment to examine the effect of office color on workers' mood and productivity. Sitting in a red or blue office, 36 subjects were asked to fill out an eight state questionnaire, measuring their mood. Partway through the experiment, subjects were guided to either continue the experiment in the same office or move to the different colored office. According to the results of the questionnaire, group differences were not statistically significant, but mean anxiety and stress scores were higher for the subjects who stayed in the red office. Mean depression scores were higher for the subjects who stayed in the blue office, and mean arousal scores were higher for the subjects who moved to the different colored office during the experiment.

Kwallek $^{9}$ conducted a study examining the effects of office wall colors on feelings of spaciousness and preference. One red office, one green and one white were evaluated by 124 undergraduate students. The results showed that the white office was perceived as the most spacious and white was chosen as the most appropriate and preferable color for an office interior. Another study by Kwallek et al. ${ }^{10}$ was designed to determine the effects of nine office colors on subjects' performance, mood and color preference. A total of 675 subjects participated in the study and gender was introduced as an additional grouping factor. The statistical analyses showed that subjects were least likely to work in orange and purple offices and preferred to work in beige and white offices. Further, females indicated more depression, confusion and anger in offices with low-saturated colors such as white, gray and beige, whereas males reported more depression, confusion and anger in high-saturated offices such as green, blue, red, yellow, and orange. One study determined that interior office color might affect perceived performance and job satisfaction. Three different color schemes were applied in three laboratory office settings where workers performed specific office tasks for 4 consecutive days. According to the results, those in the white and predominantly blue-green offices reported higher perceived performance and job satisfaction than those in the predominantly red office. ${ }^{11}$

A cross-cultural study of indoor work environments directed by Küller et al. ${ }^{12}$ aimed to determine whether indoor lighting and color would have any systematic impact on workers' moods. The study was carried out on 988 subjects in real work environments in different seasons and in countries with different latitudes, with all subjects participating in all parts of the study. The results indicated that workspace color is an important environmental factor. It was determined that the index of emotional status was higher throughout the year for those who had the most colorful work environments. According to the results, the use of good color design might contribute to a more positive mood.

The research mentioned above was mostly conducted to analyze the effects of different hues (red, green, blue, etc.) on workers' mood and performance. Still there is much to research and understand about the other two dimensions of color - value and chroma - in workplaces.

Office spaces are primarily task-oriented work environments related to the performance of visual tasks. According to Katzev, ${ }^{13}$ designing lighting for an office environment not only involves technical issues regarding the individuals' work-related tasks, but also influences workers' general motivational states, psychological wellbeing and comfort. The Standard Practice Subcommittee of the Office Lighting Committee of the Illuminating Engineering Society of North America (IESNA) ${ }^{14}$ notes that the major purpose of good lighting design in the office environment is to provide effective human visual comfort, to recognize human perception about the appearance of space and to consider energy efficient applications. IESNA sets standards and recommendations such as required illuminance levels for visual tasks, ${ }^{14}$ recommended surface reflectance values ${ }^{15,16}$ and recommended luminousity ratios between the lighting for the surface of the task and other surfaces ${ }^{14}$. These considerations imply constraints on the dimension of value.

Recent research has shown that although there are many potentially objectionable features in office environments (e.g., poor lighting, low visual comfort, etc.), users are most affected by office color design by means of their color preferences ${ }^{17}$ Thus, understanding the effect(s) of chroma in terms of task performance and environmental appraisal can contribute to providing physically and psychologically sufficient working environments that can enhance workers' well-being and productivity. The aim of this study, therefore, is to explore the effects of chroma on participants' task performances and appraisal of a fullscale office environment.

The research questions of the study were as follows:

1. Are there any differences between achromatic and chromatic color schemes of an office environment in terms of task performance?

2. Are there any differences between achromatic and chromatic color schemes in terms of appraisals of an office environment?

\section{EXPERIMENTAL STUDY}

To understand how individuals experience office environments where achromatic and chromatic color schemes have been applied, the study was carried out in a fullscale setting that was designed as an ordinary private office. In the study, it was crucial to use colors with the same value (lightness) in the achromatic and chromatic schemes to understand the effect of chroma. During the research, subject groups were given a set of task performance tests and a questionnaire. 


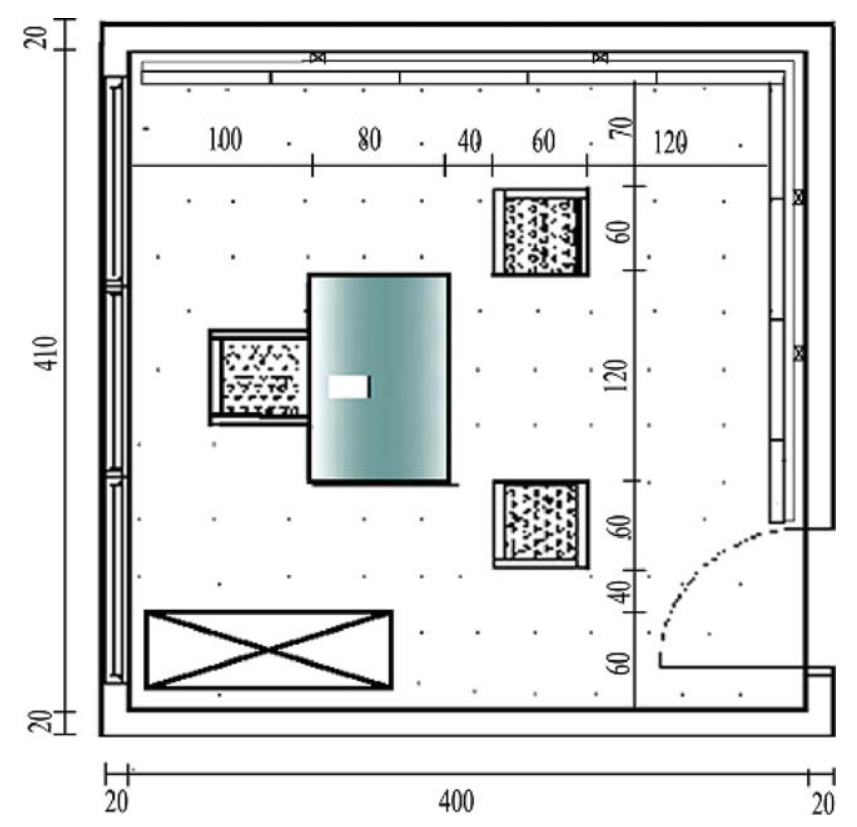

FIG. 1. The plan of the experimental room. [Color figure can be viewed in the online issue, which is available at wileyonlinelibrary.com.]

\section{The Experiment Room}

The study was carried out in an office room at the Department of Interior Architecture and Environmental Design at Bilkent University in Ankara. The room measured $4 \times 4.10 \mathrm{~m}$, and the ceiling height was $3.20 \mathrm{~m}$ (Fig. 1). The windows of the room were covered with thick black panel, preventing the penetration of daylight to control for its effect during the research. The existing general (downward) lighting with homogeneously distributed illuminance was used for the experiment. The specifications of the lighting are shown in Table I.

On two adjacent walls, a plywood sliding panel system was constructed to provide two-sided surfaces for easy implementation of the different color schemes. One side of the panels was painted with the chromatic scheme, and the other side was painted with the achromatic scheme with an equivalent achromatic gray. The natural color system (NCS) color scanner was used for measuring colors. ${ }^{18}$ Because of its low cost and ease of implementation, fabric was used as carpet the floor and upholstery for the furniture. To change the wall colors, the panels were slid to the corner and turned to the other side. The value of the colors was limited to within the range of surface reflectance recommended for office environments. ${ }^{14,15}$ For the chromatic scheme, monochromatic colors were applied to avoid the effect of contrasting hues, as this subject is not within the scope of this study (see Fig. 2). The NCS codes and surface reflectances of the applied colors are shown in Table II. The furniture, consisting of a desk, an office chair, two armchairs and a filing cabinet, was arranged so that the subjects could see three sides of the room during the experiments (including the colored wall in the chromatic scheme).

\section{Subject Groups}

The 60 subjects were randomly chosen from among the academic and administrative staff of Bilkent University and participated in the experiment voluntarily. To alternately test chromatic and achromatic schemes, the subjects were divided into two groups, according to their age and gender. One of the groups evaluated the achromatic scheme first and the chromatic scheme second, while the other group made their evaluations in the opposite way.

\section{Task Performance Tests}

Human performance measurement reflects the man-environment relationship since it is known that environmental quality impacts performance. In recent research, clerical tasks such as typing, proofreading, comparisons and cognitive performance in memory and problem-solving tasks ${ }^{19-21}$ have been used for measuring performance of subjects under different circumstances. In this study two kinds of performance tasks were used: problem solving ${ }^{22}$ and proofreading.

In the problem-solving task, 30 items were tested. Each item contained a figure with a missing piece, and involved a different principle or theme for obtaining the missing piece. Below the figure, there were either six or eight pieces to choose from to complete the figure, and only one correct answer. The proofreading task showed two paragraphs. In one paragraph, participants were asked to count how often a certain word appeared; in the other paragraph participants were asked to find the typographic errors. $^{23}$

\section{Questionnaire}

The questionnaire consisted of four parts. First, the participants were asked to evaluate their performance of the given tasks. The second part asked participants to evaluate the office environment by means of five-point semantic scales. Twelve adjective pairs were chosen: unpleasant/ pleasant, unattractive/attractive, unsatisfying/satisfying, static/dynamic, tense/relaxing, uncomfortable/comfortable,

TABLE I. Specifications of the artificial lighting of the experiment room.

\begin{tabular}{ll}
\hline Light source & $\begin{array}{c}\text { Four Philips } \\
\text { fluorescent lamps } \\
\text { (TL-D36W 840) }\end{array}$ \\
\hline $\begin{array}{l}\text { Color temperature } \\
\text { Color rendering } \\
\text { Luminary of the experiment room }\end{array}$ & $\begin{array}{l}4000{ }^{\circ} \mathrm{K} \\
85 \mathrm{Ra}\end{array}$ \\
& \\
Illuminance level on the \\
working surface (measured by \\
Minolta Illuminance Meter)
\end{tabular}



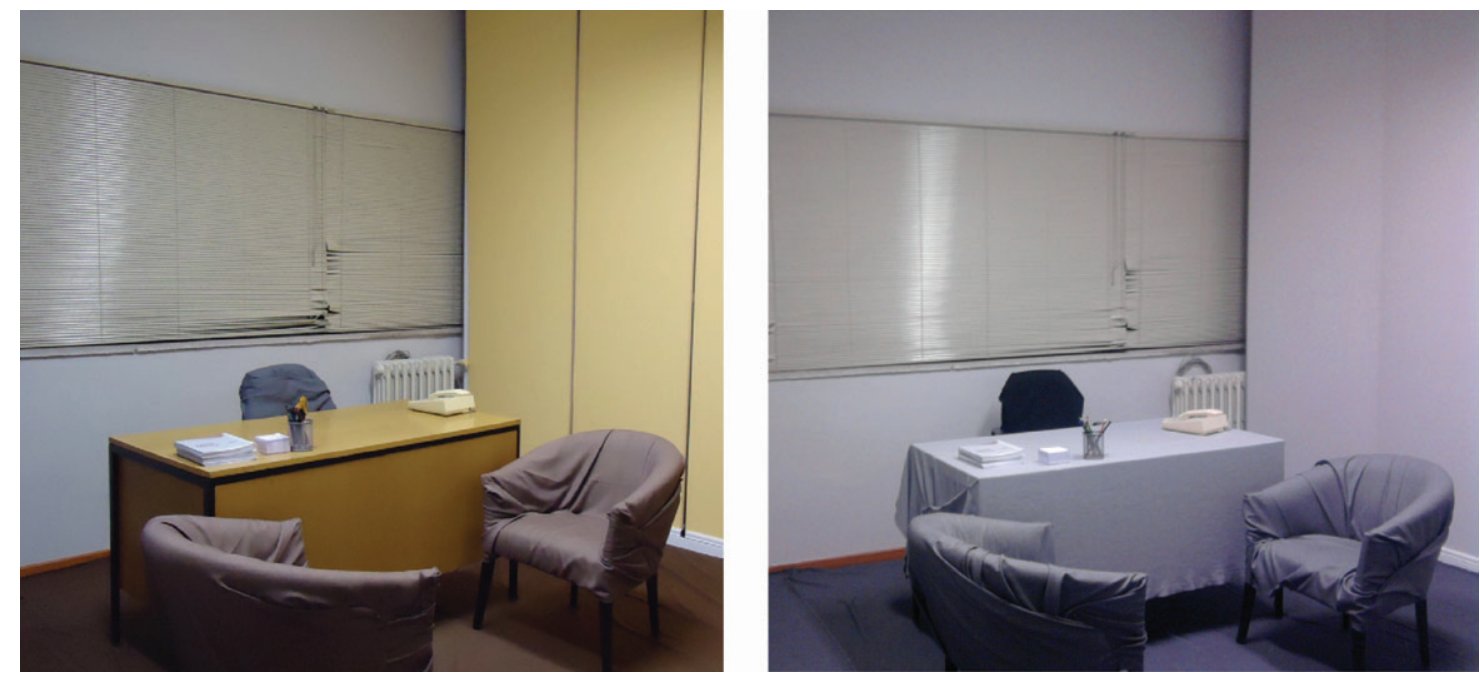

FIG. 2. The experimental room with the chromatic (left) and achromatic (right) color schemes.

disorganized/organized, nonfunctional/functional, informal/ formal, unusual/usual, discordant/harmonious, and confined/spacious. The questions of the third part asked whether participants liked, preferred and found the color schemes appropriate for an office in general and for their own office. In the final section, the subjects' further opinions, complaints and suggestions about the office settings were solicited by open-ended questions.

\section{Experimental Process}

The experiment was conducted in the following phases: the participants were taken to the experimental room one by one at scheduled time. In the experiment room, participants were first tested for color vision with the Isihara color blindness test. After a few minutes for visual adaptation, the experimental procedure was explained to them. Each participant first performed the problem-solving and proofreading tests, whereas the pollster recorded the time spent. Then they were administered the questionnaire. After these phases, participants were scheduled for the the other color scheme, with at least 4 days between the two experiments to avoid the learning effect. In the second experiment, participants performed the same kinds of tasks but with different text, and filled in the same questionnaire. The Statistical Package for the Social Sciences (SPSS) 13.0 was used to analyze the data of the study.

\section{RESULTS}

\section{Effects of Color Scheme on Task Performance}

According to Bailey ${ }^{24}$ adequate human performance can be measured by utilizing accuracy, speed of performance and user satisfaction. To investigate whether there are any differences between achromatic and chromatic color schemes of an office environment in terms of task performance accuracy and the speed of performance were analysed. The mean value of accuracy in the achromatic colored room was $43.10 / 45(\mathrm{SD}=2.11)$ and in the chromatic colored room 44.13/45 (SD $=0.98)$, differing significantly $(t=-3.89$, df $=59, P<0.001)$. The mean value of time spent on the performance tasks in the achromatic colored room was $4.80 \mathrm{~min}$. $(\mathrm{SD}=1.59)$ and in the chromatic colored room $4.33 \mathrm{~min}$. ( $\mathrm{SD}=1.33)$. These figures also differ significantly $(t=3.26$, df $=59, P=0.002)$. The figures also show that in terms of accuracy and speed the participants' performances were better in the chromatic scheme than in the achromatic scheme. However, the results of the self-reports by the participants (about their accuracy, timing and percieved effect of color scheme on their performences) showed no significant difference between the achromatic and chromatic schemes (Wilcoxon, self-reports on accuracy; $z=-1.52, P=0.129$, selfreports on timing; $z=-0.72, P=0.467$, self-reports on perceived effect of color scheme; $z=-0.97, P=0.331$ ).

TABLE II. NCS codes and reflectances of the surfaces (measured by NCS color scanner).

\begin{tabular}{|c|c|c|c|c|c|}
\hline \multicolumn{3}{|c|}{ Achromatic scheme } & \multicolumn{3}{|c|}{ Chromatic scheme } \\
\hline & NCS codes & Reflectances (\%) & & NCS codes & Reflectances (\%) \\
\hline Ceiling & S 0500N & 87 & Ceiling & S 0500N & 87 \\
\hline Walls $1-$ & S1500N & 68 & Walls $1-$ & S1500N & 68 \\
\hline $2-$ & S 3000N & 50 & $2-$ & S 3000N & 50 \\
\hline & & & $3-$ & S 0530- Y30R & 68 \\
\hline Furniture & & & Furniture & & \\
\hline Table & S 4000N & 35 & Table & S 3050 Y20R & 30 \\
\hline Armchair & S $6500 N$ & 19 & Armchair & S 4050 Y30R & 19 \\
\hline Floor & S $5500 \mathrm{~N}$ & 24 & Floor & S 5020 Y30R & 24 \\
\hline
\end{tabular}


TABLE III. Significance of semantic differences between office setups presented in the achromatic and chromatic schemes (Wilcoxon $Z$ values and Asymp. 2-tailed significancies).

\begin{tabular}{lcc}
\hline \multicolumn{1}{c}{ Adjective pairs } & $Z$ & Sig. (2-tailed) \\
\hline Unpleasant-pleasant & $-2.11^{\mathrm{a}}$ & .035 \\
Unattractive-attractive & $-1.97^{\mathrm{a}}$ & .048 \\
Unsatisfying-satisfying & $-2.44^{\mathrm{a}}$ & .015 \\
Static-dynamic & $-3.21^{\mathrm{a}}$ & .001 \\
Tense-relaxing & $-1.40^{\mathrm{a}}$ & .162 \\
Uncomfortable-comfortable & $-1.03^{\mathrm{b}}$ & .302 \\
Disorganized-organized & $-0.84^{\mathrm{b}}$ & .403 \\
Nonfunctional-functional & $-0.67^{\mathrm{a}}$ & .500 \\
Informal-formal & $-3.04^{\mathrm{b}}$ & .002 \\
Unusual-usual & $-0.18^{\mathrm{a}}$ & .857 \\
Discordant-harmonious & $-4.33^{\mathrm{b}}$ & .000 \\
Confined-spacious & $-0.88^{\mathrm{a}}$ & .380 \\
\hline
\end{tabular}

a Based on negative ranks.

b Based on positive ranks.

In the study, the same subjects performed the procedure for both the achromatic and chromatic settings. Although the order of the achromatic and chromatic settings changed for the participants alternately, the learning effect was tested to prove the reliability of the findings on performance tasks. The scores of the participants who were presented one scheme first and the scores of the others who were presented that scheme second were analyzed through independent sample $t$-tests. The results showed that there are no significant learning effects on the task peformances.

\section{Effects of Color Scheme on Appraisal of the Office Environment}

The effects of color scheme on the appraisal of the office environment were analyzed under three sections, namely, analysis of the semantic scales, analysis of the open-ended questions and analysis of the participants' evaluations on the appropriateness of the color schemes for real office environments. First, the Wilcoxon Rank test was performed to see whether there were any differences between appraisals of the office environment of the different schemes. According to the results there are significant differences between the achromatic and chromatic schemes in terms of pleasantness, attractivness, satisfaction, dynamism, formality and harmony (Table III). The negative and positive ranks explain that the office with the chromatic scheme was found to be more pleasant, attractive, satisfying and dynamic, whereas the achromatic scheme was evaluated as more formal and harmonious.

The results of the factor analysis showed that there are both similarities and differences between the appraisals of the achromatic and chromatic schemes. For the achromatic scheme, 12 adjective pairs were sorted under three factors, whereas four factors were extracted for the chromatic scheme. Table IV presents the extracted factors, accounted percentages of the factors and factor loadings of the adjectives for both schemes. The results showed that pleasantness and dynamism from the first factor and harmony from the second factor under "achromatic scheme" were categorized as a new - fourth factor under "chromatic scheme."In addition, spaciousness was dissociated from formality (informal/formal) and familiarity (unusual/usual), and joined with functionality (nonfunctional/functional) and order (disorganized/organized).

Second, the appropriateness of the color schemes for real office interiors was evaluated by asking subjects whether they liked, preferred and found applicable the color schemes for an/their own office. The results indicated that there was no significant difference between the achromatic and chromatic schemes in terms of pleasentness, preference and applicability of the color schemes (pleasentness; $z=-1.281, P=0.200$, preference; $z=$ $-1.199, P=0.231$ applicability $z=-1.756, P=0.079$ ). From the frequency distribution of each in the achromatic and chromatic schemes, it can be interpreted that partici-

TABLE IV. Extracted factors, accounted percentages of factors and factor loadings of adjectives for the achromatic and chromatic schemes.

\begin{tabular}{|c|c|c|c|c|}
\hline \multicolumn{3}{|c|}{ Achromatic scheme } & \multicolumn{2}{|c|}{ Chromatic scheme } \\
\hline \multirow[t]{7}{*}{ Factor 1} & Unpleasant-pleasant & 0.85 & Unattractive-attractive & 0.84 \\
\hline & Unattractive-attractive & 0.83 & Uncomfortable-comfortable & 0.84 \\
\hline & Unsatisfying-satisfying & 0.74 & Unsatisfying-satisfying & 0.69 \\
\hline & Tense-relaxing & 0.73 & Tense-relaxing & 0.68 \\
\hline & Static-dynamic & 0.65 & & \\
\hline & Uncomfortable-comfortable & 0.62 & & \\
\hline & & $29 \%$ & & $25 \%$ \\
\hline \multirow[t]{5}{*}{ Factor 2} & Discordant-harmonious & 0.82 & Disorganized-organized & 0.75 \\
\hline & Informal-formal & 0.80 & Nonfunctional-functional & 0.73 \\
\hline & Unusual-usual & 0.65 & Confined-spacious & 0.70 \\
\hline & Confined-spacious & 0.64 & & \\
\hline & & $20 \%$ & & $15 \%$ \\
\hline \multirow[t]{3}{*}{ Factor 3} & Nonfunctional-functional & 0.81 & Unusual-usual & 0.84 \\
\hline & Disorganized-organized & 0.80 & Informal-formal & 0.74 \\
\hline & & $16 \%$ & & $14 \%$ \\
\hline \multirow[t]{3}{*}{ Factor 4} & & & Static-dynamic & 0.76 \\
\hline & & & Discordant-harmonious & 0.69 \\
\hline & & & Unpleasant-pleasant & 0.60 \\
\hline
\end{tabular}


pants did not like, prefer or find appropriate any of the color schemes for their own offices.

Finally, open-ended questions on different color schemes were examined to obtain additional interpretation and suggestions by the participants. The findings showed that participants felt the office environment with the achromatic scheme was monotonous, boring, simple and artificial, while the chromatic scheme was found to be cozy, pleasant, and restful, but also calm and boring. For both color schemes, participants complained about the quality of the artificial lighting, lack of daylight, lack of outside view and lack of items related to affinity, attachment, and decoration. The majority of the participants criticized the lack of colors for both schemes; they suggested the addition of any color(s) for achromatic scheme, with bright (strong chroma) colors most frequently suggested.

\section{DISCUSSION}

In the literature, there are no studies comparing achromatic and chromatic color schemes in office environments; prior research generally focuses on examining the effects of hue. ${ }^{6-11}$ In this experiment, the differences between achromatic and chromatic schemes were analyzed through task performance tests and a questionnaire for measuring appraisal of the environment. The experiment was designed as a full-scale setup, because other visualization/simulation techniques have been shown to be questionable when light and color effects are studied together. ${ }^{6,17}$ In the study, the IESNA's technical recommendations for surface reflectance for visual comfort and energy saving were taken into consideration, and the value of the surface colors were kept constant in both schemes. To analyze performance, the subjects were asked to participate in problem-solving and proofreading tasks. The self-reports of the subjects were also recorded.

\section{Evaluation of Participants' Task Performances}

This research indicates a significant effect of chroma on the performance of office workers; the findings show that there are significant differences between achromatic and chromatic color schemes in an office environment in terms of task performance scores (measurements of accuracy and speed). However, there is no significant difference in self-reports of the tasks by the participants. According to the analysis of task performance, it was found that participants performed better in the chromatic scheme than in the achromatic scheme. This result shows similarities with previous studies in the literature. Kwal$\mathrm{lek}^{25}$ studied workers' performance in white, green and red office interiors and the results indicated that participants made significantly more errors in the white office than participants in the red and green offices. In a study on the effects of nine different hues on workers' productivity, the findings showed that participants performed worse in the white office interior than in offices with any of the other hues. ${ }^{10}$ However, in this study, the results of self-reports of the task performance indicated that there was not a significant difference between achromatic and chromatic schemes. This result is similar to a experiment that examined the effects of study environments on adult students' mood, satisfaction, motivation, and performance; it was found that task perception was not affected by the variables of environment. ${ }^{26}$ In this study, the analysis of adjective pairs showed that the office environment with the chromatic scheme was found to be more pleasant, attractive, satisfying, and dynamic than the office environment with the achromatic scheme. Such impressions by the participants about the chromatic scheme possibly led to better performance in the chromatic color scheme.

\section{Evaluation on Participants' Appraisals of the Office Environment}

The statistical analysis shows that participants found the office environment with the chromatic scheme more pleasant, attractive, satisfying, and dynamic than the office environment with the achromatic scheme. These results are similar to a study examining the impact of light and color on the mood of indoor workers', ${ }^{12}$ since pleasantness, attractivity, satisfaction and dynamism have positive effects on emotional status. Yet, these results differed from a study by Küller et al. about arousal in multicolored and gray spaces. ${ }^{27}$ They found that there is no difference between multicolored and gray spaces in terms of pleasantness. This contradiction may be caused by other dynamics of the multicolored scheme applied, as color combinations house complex relations among color dimensions.

This study also indicates a significant effect of chroma on evaluations of harmony and dynamism (the achromatic scheme was found more harmonious and the chromatic scheme was found more dynamic). The construct of "harmony" is synonymous with and/or covered by "unity" in most languages/terminology, and "dynamism" mostly associates with "energy," "variability," "multiplicity" and hence "complexity" - at least within the context of color constructs. Therefore, the effects of chroma on harmony and dynamism in this study are similar to those found by Küller et $a l .{ }^{27}$ who recorded high unity values in the gray room, while complexity scores were high in the colorful room.

The result of factor analysis not only supports the significant difference between the appraisals of the achromatic and chromatic color schemes in this study, but also indicates a more complex relationship between color constructs in the dimension chroma. For the achromatic scheme adjectives related with pleasure, arousal and comfort are categorized under same factor, while harmony and spaciousness go together with formality and usuality. However, for the chromatic scheme, harmony is matched with dynamism and pleasantness, and spaciousness is connected to organization and function. This finding implies the altering nature of harmony and spaciousness in color research, especially within the context of architectural space. $^{28}$ 
The results of this study also indicate that there is no significant difference between the "appropriateness" of presented achromatic and chromatic schemes for subjects' own offices, which is contrary to the ratings of the adjective pairs. This paradox can be explained by the participants' unfamiliarity with color schemes of experimental setups, which may look artificial compared to real settings, where many items of varying colors are in offices with usually white or off-white walls. ${ }^{29}$ Likewise, Kwallek $^{9}$ found that among the three offices with white, red and green walls, subjects rated the white office as the one they would most like to work in and considered white as the most appropriate color for an office wall. The study by Kwallek et al. ${ }^{10}$ also supports this finding, indicating that individuals preferred to work in beige and white rooms significantly more than in red, blue, yellow, purple, or orange rooms. Moreover, in one of the experiments examining the effects of red, green and white office environments on worker productivity and mood, it was found that the subjects in the white office reported that they would like to work in this environment because they regarded white environments as sterile and conductive to work. $^{25}$ Therefore, it can not be ignored that to some extent, color preference is guided by an environmental or social context, given the predominance of a white or off-white color palette in most commercial spaces, office settings and institutions.

In this study participants complained about the artificial lighting, lack of daylight, lack of outside view and lack of items related to affinity, attachment and decoration in the experiment room. Such feelings may have led the participants to not prefer either of the color schemes. It has been demonstrated in the literature that there is a strong preference for windows in offices to allow the penetration of daylight and provide a view to the outside. ${ }^{30-32}$ Moreover, participants suggested adding (any) color(s) to the achromatic scheme, with bright (strong chroma) colors the most frequently suggested. This finding emphasizes the need and importance of color and color design in the architectural space.

\section{Evaluation of Chroma Effects}

The study concluded that there are similarities and differences between achromatic and chromatic schemes in terms of task performance and appraisal. It was found that the office environment with the chromatic scheme was evaluated as more pleasant, attractive, satisfying and dynamic than the office with the achromatic scheme, and participants' performance was better in the chromatic scheme than their performance in the achromatic scheme. As seen in the literature, environmental appraisals embody individuals' judgments about places from their own experiences and psychological constructs (such as meaning, concern, and preference). The variety of personal and environmental characteristics and interactions between them influence appraisals. Personal characteristics include such aspects as culture, age, gender, and familiarity with the space, whereas environmental characteristics can include room design, complexity, contrasts, architectural style, and contents. ${ }^{33}$ The results of this study are useful for interior designers in general and for designers who use color as an element to enhance environmental quality. The ubiquitous use of white walls and dark office furniture should be reconsidered, perhaps with an aim to create more dynamic and visually comfortable workplaces. In some experimental studies of color, applications of very strong colors resulted in undesirable responses.

In this study, however, it was initially seen that a moderate increase in the use of good color design can improve workers' overall comfort and productivity. For future studies and experiments, note that the specific colors that will be used in the office environment experiments is an important factor. ${ }^{34}$ To understand whether the effect of a specific color is because of its hue, its chroma (saturation) or its value (lightness), at least one of the three dimensions of color should be the same to control the variables. This study concentrated on examining the effect of chroma in the office environment; the other dimensions of color were controlled for in both schemes. Further research could explore the effect of the other two dimensions of color. A limitation of this study is that only a yellow-red monochromatic scheme was used in the comparison between achromatic and chromatic schemes; cool colors and/or complementary color schemes could be studied to achieve extensive results. The findings also pointed out notable affectibility against chroma for the constructs "harmony" and "spaciousness." Future research concentrating particularly on these constructs would sustain a comprehensive conclusion, especially within the context of architectural space.

Further studies could also explore any demographic effects, such as age, gender and profession, on task performance and the assessment of different color schemes; these factors were not considered in this study. Moreover, in this study the age of participants ranged between 22 and 65 years old, which is a wide range to control for the effects of variables on impressions and performance. In the further studies, the age range of participants should be limited to control for the effects of age in measuring the hypothesis.

\section{ACKNOWLEDGMENTS}

The authors are grateful to Bilkent University, Department of Interior Architecture and Environmental Design in Ankara, Turkey for funding the experimental room.

1. Smith D. Environmental coloration and/or the design process. Color Res Appl 2003;28:360-365.

2. Birren F. Color and Human Response. NY: Van Nostrand Reinhold; 1978.

3. Faulkner W. Architecture and Color. NY: Wiley - Interscience; 1972.

4. Visher CJ. Workspace Strategies: Environment as a Tool of Work. NY: Chapman \& Hall; 1996.

5. Sundstrom E. Work Places: The Psychology of the Physical Environment in Offices and Factories. Cambridge: Cambridge University Press; 1986. 
6. Kwallek N, Woodson H, Lewis CM, Sales C. Impact of three interior color schemes on worker mood and performance relative to individual environmental sensitivity. Color Res Appl 1997;22:121-132.

7. Jacobs KW, Hustmyer FE. Effects of four psychological primary colors on GRS, heart rate, and respiration rate. Percept Motor Skill 1974;38:763-766.

8. Kwallek N, Lewis CM, Robbins AN. Effects of office interior color on workers' mood and productivity. Percept Motor Skill 1988;66: $123-128$.

9. Kwallek N. Office wall color: An assessment of spaciousness and preference. Percept Motor Skill 1996;83:49-50.

10. Kwallek N, Lewis MC, Lin-Hsiao JMD, Woodson H. Effects of nine monochromatic office interior colors on clerical tasks and worker mood. Color Res Appl 1996;21:448-458.

11. Kwallek N, Soon K, Woodson H, Alexander JL. Effect of color schemes and environmental sensitivity on job satisfaction and perceived performance. Percept Motor Skill, 2005;101:473-486.

12. Küller R, Ballal S, Laike T, Mikellides B, Tonello G. The impact of light and color on psychological mood: A cross-cultural study of indoor work environments. Ergonomics 2006;49:1496-1507.

13. Katzev R. The impact of energy-efficient office lighting strategies on employee satisfaction and productivity. Environ Behav 1992;24: 759-778.

14. Standard Practice Subcommittee of the Office Lighting Committee of the IESNA. American National Standard Practice for Office Lighting. (RP.1). NY: Illuminating Engineering Society of North America; 1993.

15. CIBSE CODE. Code for Interior Lighting, California: Yale Press; 1984.

16. Gordon G, Nuckolls JL. Interior Lighting for Designers, NY: Wiley; 1995.

17. Yilmazer S, Ural SE, Tanröver S. A discussion on spatial color design with the emphasis on technical specifications: Energy efficiency and visual quality, in the proceedings of the Lux Europe 2009 - International Congress, İstanbul, Turkey, 9-11 Sept. 2009, pp. 59-66.

18. NSC Color Scanner. Retrieved April 28, 2010 from http://www.ncscolor. com/en/lm/solutions/ncs-favourites/colorscan/

19. Knez I. Effects of indoor lighting on mood and cognition. J Environ Psychol 1995;15:39-51.
20. Veitch JA, Newsham GR. Lighting quality and energy-efficiency effects on task performance, mood, health, satisfaction and comfort. J Illum Eng Soc 1998;27:107-130.

21. Kwallek N, Soon K, Lewis CM. Work week productivity, visual complexity, and individual environmental sensitivity in three offices of different color interiors. Color Res Appl 2007;32:130-143.

22. The Raven's Progressive Matrices. Retrieved April 28, 2010 from http://en.wikipedia.org/wiki/Raven's_Progressive_Matrices.

23. Ozturk E and Yilmazer S. An Experimental Study on Task Performance in Workplace Applied with Achromatic and Chromatic Color Scheme, International Conference- Colour and Light in Architecture, 11-12 November 2010, Venice, Italy.

24. Bailey RW. Human Performance Engineering: A Guide for System Designers. NJ: Prentice-Hall, Inc; 1982.

25. Kwallek N, Lewis, CM. Effects of environmental color on males and females: A red or white or green office. Appl Ergon 1990;21:275-278.

26. Stone NJ. Designing effective study environments. J Environ Psychol 2001;21:179-190.

27. Küller R, Mikellides B. Janssens J. Color, arousal, and performance-A comparison of three experiments. Color Res Appl 2009;34:141-152.

28. Ural SE, Yilmazer S. Architectural Color Design Process: An Evaluation on Sequential Media via Semantic Ratings, Color Res Appl 2010;35:343-351.

29. Mahnke FH. Color, Environment and Human Response. New York: Van Nostrand Reinhold; 1996.

30. Galasiu AD, Veitch JA. Occupant preferences and satisfaction with the Luminous environment and control systems in daylight offices: A literature review. Energ Buildings 2006;38:728-742.

31. Menzies GF, Wherrett JR. Windows in workplace: Examining issues of environmental sustainability and occupant comfort in the selection of multi-glazed windows. Energ Buildings 2005;37:623-630.

32. Manav B. An experimental study on the appraisal of the visual environment at offices in relation to color temperature and illuminance. Build Enviro 2007;42:979-983.

33. Gifford R. Environmental Psychology: Principles and Practice. 3rd Ed. Colville, WA: Optimal Books; 2002.

34. Öztürk E. The Effects of Color Scheme on the Appraisal of an Office Environment and Task Performance, Master Thesis Supervised by Yilmazer S, Bilkent University, Ankara, 2010.

\section{Publications Briefly Mentioned}

\section{CIE 203:2012 A Computerized Approach to Transmis- sion and Absorption Characteristics of the Human Eye, CIE Central Bureau, Vienna, 2012 pp 66 ISBN 9783 902842411 EUR 135.}

There has long been a need for a series of reference spectral transmission and absorption data for the human eye for applications in eye research and optical safety studies. TC 6-15 collected spectral data from the literature and determined from that literature the best form for the wavelength dependence of the transmission and absorption of the components of the human eye. After critical review, the data have been compiled in tabular form in comma-delimited computer-accessible data files. The tabulated data consist of the transmission and absorption data of the clear ocular media, including the cornea, the aqueous, the lens, and the vitreous of the young $(<10$ years old) human eye and the rhesus eye for the wavelength range of $0.2-2.5 \mu \mathrm{m}$. Transmittance data of the total clear ocular media in the human eye for the wavelength range 0.3-0.7 $\mu \mathrm{m}$ and for ages between 1 year and 100 years are also tabulated. These data can be downloaded by readers of this Technical Report from the CIE website.

Leo Trausnith

Published online 18 July 2012 in Wiley Online Library (wileyonlinelibrary.com). DOI $10.1002 / \mathrm{col} .21759$ 